\title{
Cerebral Arterial Aneurysm
}

National Cancer Institute

\section{Source}

National Cancer Institute. Cerebral Arterial Aneurysm. NCI Thesaurus. Code C101022.

A balloon type pouch or bulge in the wall of a cerebral artery. 